\section{NO PRINCÍPIO É O LUDENS: INTEGRAÇÃO DO SELF DO BEBÊ ATRAVÉS DO BRINCAR EM CRECHE}

\author{
IN THE BEGINNING IS LUDENS: INTEGRATION OF THE INFANT'S SELF \\ THROUGH PLAYING AT NURSERY SCHOOL
}

\author{
AL PRINCIPIO ES EL LUDENS: INTEGRACIÓN DEL SELF DEL BEBÉ A TRAVÉS \\ DEL JUGAR EN LA GUARDERÍA
}

\section{Danielle Menezes de Oliveira Gonçalves*, Pierre Normando Gomes-da-Silva**, Fernando Cézar Bezerra de Andrade**}

\begin{abstract}
Palavras chave:
Recreação.

Lactente.

Educação infantil.

Resumo: Objetiva-se analisar o processo de integração do self do bebê em seu brincar. Trata-se de pesquisa descritiva, qualitativa, etnográfica, cujos dados foram coletados por observação participante em 72 horas ao longo de dois meses, com 12 lactentes envolvidos em recreação em creche pública. Considerando movimento, comunicação e expressão de intencionalidade, as brincadeiras dos bebês foram examinadas para identificar criatividade em ações fluentes, focalizadas e constantes. Esses sujeitos escolheram objetos inanimados para brincar, do que se inferiu sentirem necessidade de manipulação e posse. As ações dos bebês foram interpretadas, segundo a teoria de Winnicott sobre 0 desenvolvimento psíquico, como evidência de um estado de quase alheamento, levando a concluir que experimentaram o brincar como atividade que concorreu para integrarem seus selves como unidade, integrando-se também a seu entorno ambiental. Logo, o brincar merece mais compreensão e valorização por profissionais da Educação Infantil.
\end{abstract}

Keywords:

Recreation.

Infant.

Nursery Schools

Palabras clave: Recreación.

Lactante.

Educación Infantil

Abstract: This article analyzes the process of integration of the infant's self when playing. It is a descriptive, qualitative, ethnographic research. Data were collected with 12 nurslings from a Public Nursery School for 72 hours during recreation time. Considering their movements, communication, and expressed intentionality, infants' play was examined in order to identify creativeness in frequent, fluent and focused actions. Those subjects choose inanimate objects to play with, which allows inferring their need for possessing and manipulating objects. According to Winnicott's theory, their actions were interpreted as evidence of as a state of almost complete absent-mindedness, which suggests that they experienced playing as an activity integrating their selves as oneness, also integrating with their environments. Therefore, playing deserves understanding and appreciation by professionals at Nursery Schools.

Resumen: El texto analiza el proceso de integración del self del bebé en el acto de jugar. Esta es una investigación descriptiva, cualitativa, etnográfica, cuyos datos fueron recolectados mediante observación participativa, durante 72 horas y a lo largo de dos meses, con 12 lactantes en una guardería pública durante la recreación. Considerando movimiento, comunicación y expresión de intencionalidad, los juegos de los bebés fueron examinados con el fin de identificar creatividad en las acciones espontáneas, enfocadas y constantes. Los sujetos escogieron objetos inanimados para jugar, lo que permite inferir la necesidad de posesión y manipulación. Las acciones de los bebés fueron interpretadas según la teoría de Winnicott sobre el desarrollo psíquico, como evidencia de un estado de casi enajenación, lo que lleva a concluir que los bebés experimentaron el jugar como actividad que contribuyó a integrar sus selfs como unidad, integrándose también a su entorno ambiental. Se concluye que el jugar merece más comprensión y valorización por parte de los profesionales de la Educación Infantil.
* Prefeitura Municipal de João Pessoa, $\mathrm{PB}$, Brasil.

E-mail: dmo.danimenezes@gmail.com

** Universidade Federal da Paraíba (UFPB). João Pessoa, PB, Brasil. E-mail: pierrenormandogomes-dasilva@gmail.com; frazec66@gmail.com

Recebido em: 25-04-2016 Aprovado em: 06-05-2017

(c) (1) (8) Licence 


\section{INTRODUÇÃO}

A antiga creche, com objetivo de cuidar assistencialmente de bebês das famílias operárias, assumiu caráter educacional, de modo a ser integrada à Educação Infantil (NYLANDER et al., 2012). De fato, famílias têm buscado essas instituições como apoio na educação dos seus filhos, que, por vezes, passam mais tempo nestas do que com os pais, assim o cuidado do bebê tem sido comumente dividido entre os pais e a escola de Educação Infantil.

Antes tida como prejudicial ao desenvolvimento afetivo e social de crianças, a creche passou a ser considerada como complementar à ação da família, com finalidade de promover o desenvolvimento integral da criança (AMORIM; ANJOS; ROSSETI-FERREIRA, 2012), de modo que os pais estão atentos àquilo que a escola pode oferecer, criando expectativa para a contribuição desta para o futuro dos seus filhos (BORDIN; SOUZA; KUNZ, 2014).

Tal mudança histórica decorreu também do desenvolvimento científico. Cresce 0 número de pesquisas sobre o brincar e interação de crianças, inclusive bebês, desenvolvendose, assim, perspectivas teóricas que explicam melhor o desenvolvimento infantil tanto em sua dimensão motora quanto cognitiva e socioafetiva (BERNARDINO; KAMERS, 2000; FRANCHI; VASCONCELOS et al., 2003; BRESSANI; BOSA; LOPES, 2007; OLIVEIRA, 2009; PÉREZRAMOS, 2009; ROSSETTI-FERREIRA et al., 2011; AMORIM; ANJOS; ROSSETTI-FERREIRA, 2012).

Não obstante, há poucos estudos sobre a prática pedagógica com bebês, em especial do docente de Educação Física (SILVA et al., 2012; SIMON; KUNZ, 2014; BORDIN; SOUZA; KUNZ, 2014), provavelmente em razão do que ponderam Nylander et al. (2012) sobre 0 descompasso entre legislação e políticas de formação profissional para a Educação Infantil, ainda eivada de representações que a associam ao assistencialismo informal e precário.

Nesse contexto, vêm sendo desenvolvidas pesquisas sobre o brincar do bebê junto ao Laboratório de Estudos e Pesquisas em Corporeidade, Cultura e Educação -LEPEC/UFPB (GONÇALVES, 2012; OLIVEIRA; GOMES-DA-SILVA, 2013), entendendo que as situações de aprendizagem precisam ser qualitativamente elaboradas para oferecer um conhecimento do mundo, ampliar diversidade de relações e possibilitar produção de linguagem. Essa é a proposição teórico-metodológica da Pedagogia da Corporeidade, construída há mais de uma década por esse laboratório (GOMES-DA-SILVA, 2011; 2014; 2015; 2016). Ela reconhece 0 valor de brincar como algo em si, sem ocupação demasiada com seus usos pedagógicos, com o conteúdo da brincadeira, mas olhando a criança que brinca, como recomenda Winnicott (1975, p. 60): "O brincar precisa ser estudado como um tema em si mesmo".

Portanto, buscamos entender, no ambiente escolar, o brincar do bebê como experiência em que também pode incidir a intervenção educacional de profissionais que, como docentes de Educação Física, sejam responsáveis por promover o pleno desenvolvimento infantil através das práticas pedagógicas.

Presumir que o lúdico esteja na origem do psiquismo não é demasiado, quando se reconhece que, desde muito cedo, os seres humanos recorrem à criatividade prazerosa para organizar as distinções fundamentais entre subjetividade e objetividade - sempre através das relações com os objetos, consigo mesmos e com outros humanos. 
Essas ações não se explicam exaustivamente sem que nelas se enxergue a expressão do brincar infantil e, com ele, da constituição do self a partir da construção da própria identidade. Todos esses processos passam pela corporeidade, entendendo-a como configuração existencial do ser no entorno em que vive. Tomamo-la como instância básica de conhecimento de si e do mundo, ou seja, é a experiência de interação com o ambiente e com a ocupação do tempo que constitui o sujeito (GOMES-DA-SILVA, 2011).

O brincar é, portanto, uma situação de movimento que professores de Educação Física devem favorecer de modo intencional, sensível e motivador. A teoria winnicottiana, apresentada na primeira parte deste artigo, é empregada para analisar um episódio lúdico de um bebê em creche, descrito mais adiante, comentando-se, ao final, implicações dessa análise para a Educação Infantil.

\section{BEBÊS QUE JÁ BRINCAM NA ESCOLA DE EDUCAÇÃO INFANTIL: O OLHAR WINNICOTTIANO}

Quando se trata da ludicidade infantil ou especificamente do brincar do bebê, a psicanálise winnicottiana oferece um paradigma esclarecedor, por tratar minuciosamente dos primórdios da formação psíquica e, nela, atribuir valor de destaque ao brincar. Conforme tal modelo teórico, o bebê é sujeito de ação e criação, mas precisa dum ambiente que viabilize seu potencial criativo. Esse potencial é suposto como um fenômeno cuja realização é essencial à vida: concerne ao modo como a pessoa se relaciona com a realidade externa, sem perda do sentido pessoal de existência (DIAS, 2003). Assim, toda criança precisa criar seu próprio mundo e dotá-lo de significado.

Ora, a complexa dinâmica entre subjetividade do bebê e ambiente que the serve de contexto leva à integração psíquica do sujeito. Ela, por sua vez, promove a unidade do self, entendido como culminância de uma experiência vital complexa que reúne 0 eu consciente e os impulsos inconscientes e descreve "[...] a pessoa concreta que se vale desse esquema [ego corpóreo] devidamente constituído" (Loparic, 2000, p. 386). Está associada à criatividade, baseada em uma tendência inata do indivíduo ao amadurecimento. Todavia, requer condições ambientais favoráveis para que se estabeleça.

Winnicott (2005/1965, p. XIX) salienta: "Não podemos nem mesmo ensiná-las a andar, mas sua tendência inata para andar em certa idade precisa de nós como figura de apoio". Do mesmo modo que os fundamentos genético-orgânicos da vida física devem ser deixados intactos para que se manifestem de modo adequado, assim também acontece na vida mental. A atribuição do ambiente facilitador é proporcionar condições adequadas para seu amadurecimento, sustentar emocionalmente esse novo ser.

Considerando a integração como a capacidade do bebê sentir-se uno, vivenciando o self como uma unidade, o brincar é situação que se presta à análise do processo de integração. Winnicott (1975) acredita que brincar é sinônimo de viver criativamente e constitui a principal experiência de descoberta e fortalecimento do self, estendida por toda vida.

Winnicott (1975) dispensou enorme atenção ao ato de brincar, destacando o valor deste em termos de um viver criativo e da descoberta do self. Para ele, o brincar se situa na área intermediária entre a realidade interna e a externa, entre a criatividade primária e a percepção 
objetiva. Nessa área, ambas as realidades encontram-se, pois, e se separam. Essa dimensão, não por acaso, é a base sobre a qual se apoia toda experiência cultural, e, nela, o brincar, a criatividade (ABRAM, 2000). Esta área faz parte do desenvolvimento do bebê e permanece em todos nós sob a forma de espiritualidade, de arte, de poesia, música, enfim, de tudo aquilo que não exige uma definição exata do que é interno ou externo.

No brincar se constitui o coletivo, e também o individual, situando-se, por isso, o brincar como base necessária à integração, à constituição do self: ele funciona como um indicador do desenvolvimento e do sentimento de ser do bebê, por meio de um viver criativo e da autodescoberta. Por ele se dão a expressão da agressividade e o controle da ansiedade; mais adiante, a experiência e a integração do self, e o surgimento da amizade: "O brincar facilita o crescimento, o brincar conduz aos relacionamentos grupais, o brincar pode ser uma forma de comunicação" (WINNICOTT, 1975, p.63). Por isso, o brincar tem a insubstituível função de promover e indicar a humanização do sujeito, não devendo ser menosprezado.

Daí se entende por que a Educação Infantil e, nela, a Educação Física, numa perspectiva mais lúdica, possam também funcionar como constituintes de sujeitos criativos, caso atentem para as iniciativas primárias dos bebês no esforço de constituírem-se sujeitos, visíveis nas menores ações que possam ser dotadas de significado, caracterizáveis como criação por meio de brincadeiras. Isso pode ser demonstrado a partir da análise de um ilustrativo episódio de atividade livre do bebê, coletado em pesquisa de campo, após descrevermos brevemente como se realizou o procedimento de coleta, por meio da observação direta.

\section{MÉTODO: OBSERVANDO O BRINCAR DO BEBÊ NA ESCOLA DE EDUCAÇÃO INFANTIL}

A brincadeira aqui analisada consiste num excerto de pesquisa descritivo-interpretativa (GIL, 2002) cuja abordagem foi qualitativa (MINAYO, 1996) e desenho de inspiração etnográfica, ao registrar, em 72 horas de filmagem durante oito semanas, a conduta de 12 bebês entre sete $e$ 24 meses, matriculados e adaptados por mais de quatro semanas, com permanência diária de no mínimo oito horas, em situações de brincadeira, num Centro de Referência da Educação Infantil$\mathrm{CREl}$, pertencente à rede pública de ensino em João Pessoa/PB, escolhido por possuir berçário, não ter previsto reformas que paralisassem a instituição e ter recebido apoio de sua gestora.

As filmagens, escolhidas por captarem fatos e processos "[...] rápidos ou complexos para o olho humano" (FLICK, 2005, p. 162) foram orientadas por roteiro para identificar e registrar o movimento expressivo do brincar dos bebês em sua rotina. Para apreciação da atividade livre do bebê (sem a intencionalidade do educador), recorreu-se a Gomes-da-Silva (2011; 2016), cuja teoria pedagógica descreve um fenômeno associável à brincadeira: a graça do jogo, encarada como a ambiência da situação de movimento que absorve o jogador, mantendo-o num modo de interação criativo com o entorno, estando atento, perceptivo e ativo na circunstância. A atividade livre do bebê é aqui entendida como brincadeira, ou seja, ocupação do tempo em que absorve quem brinca, favorecendo a interação criativa com o entorno, sem, todavia, presença ou consciência de regras. Brincar ou jogar aqui não está caracterizado pelo aceite e submissão às regras coletivas, mas principalmente por esse estado de graça vivido em qualquer tipo de jogo. Assim o jogo para a Pedagogia da Corporeidade (PC) é caracterizado, essencialmente, como uma situação de movimento em que se experimenta a absorção do jogador com a consequente ação criativa em resposta a circunstância. 
Para inferir os significados dessa situação de movimento vivida associamos a descrição da experiência a partir da análise de Laban (1978). Segundo ele, o motivo do movimento corporal é a necessidade de expressão de impulsos internos, denominados esforços, organizados em função de quatro fatores que os modulam e organizam: fluxo, espaço, peso e tempo.

O fluxo requer precisão dos movimentos e a atitude que lhe está relacionada é o entusiasmo. Assim, é perceptível na progressão do movimento, que pode ter tensão muscular livre ou controlada. Esse fator informa como o movimento ocorre: mais ou menos liberado ou mais ou menos contido, envolvendo a emoção e o relacionamento (GONÇALVES, 2012; COSTA, 2010; FERNANDES, 2006).

O espaço relaciona-se com a atenção, o tipo de concentração, que pode ser direta ou flexível. Tal fator considera a atenção do olhar ou partes do corpo na forma como se ocupa o ambiente, informando sobre onde o movimento se dá: um ou único mais focos no espaço ao mesmo tempo (GONÇALVES, 2012; COSTA, 2010; FERNANDES, 2006).

O peso refere-se à determinação e, portanto, a intenção a ele se relaciona. Não à toa, esse fator envolve firmeza de propósito e força de vontade, auxiliando na assertividade e proporcionando estabilidade e segurança. O peso informa sobre "o quê do movimento" e as qualidades do esforço implicado são leve e firme (GONÇALVES, 2012; COSTA, 2010; FERNANDES, 2006).

Por sua vez, o tempo relaciona-se com a atitude de escolha, a decisão, informando sobre quando o movimento se passa, isto é, sua continuidade (prolongado/rápido) ou velocidade (súbito, curto/lento). Envolvendo duração e ritmo, esse fator proporciona maior mobilidade e tolerância em relação às frustrações inerentes à execução de movimentos (GONÇALVES, 2012; COSTA, 2010; FERNANDES, 2006).

Não existe movimento que não possua esses quatro fatores. 0 movimento, com suas diferentes formas, ritmos, pesos e fluências, é revelador e possibilita demonstrações da personalidade de cada um (MOMMENSOHN; RENGEL, 1992).

Fundamentados nesses conceitos, adotaram-se como signos da comunicação os movimentos e as atitudes do brincante, buscando inferir os impulsos internos que orientavam o seu comportamento, a fim de identificar-se a integração do bebê ao brincar. Com isso, obtiveram-se categorias de análise: liberdade de escolha, satisfação, concentração e domínio do objeto em sua relação com os fatores de movimento descritos por Laban (1978), como se apresenta no Quadro 1.

Quadro 1 - Relação das categorias de análise com os fatores de movimento

\begin{tabular}{|c|c|c|c|c|}
\hline FATORES & Tempo & Fluxo & Espaço & Peso \\
\hline CATEGORIAS & Liberdade de Escolha & Satisfação & Concentração & Domínio do Objeto \\
\hline DEFINIÇÕES & $\begin{array}{l}\text { Tomada de decisão - a } \\
\text { execução do brincar, } \\
\text { a duração, o ritmo, a } \\
\text { mobilidade, a escolha dos } \\
\text { objetos e tolerância em } \\
\text { relação às frustrações. }\end{array}$ & $\begin{array}{l}\text { Entusiasmo na } \\
\text { ação - as emoções } \\
\text { e as relações com } \\
\text { o outro (objeto } \\
\text { ou pessoa) ao } \\
\text { brincar. }\end{array}$ & $\begin{array}{l}\text { Capacidade } \\
\text { de atenção - a } \\
\text { concentração, } \\
\text { a relação com } \\
\text { o ambiente, ao } \\
\text { brincar. }\end{array}$ & $\begin{array}{l}\text { Intenção para } \\
\text { agir - a disposição, } \\
\text { a percepção, a } \\
\text { firmeza de propósito } \\
\text { ao brincar. }\end{array}$ \\
\hline
\end{tabular}


Adotaram-se todos os cuidados necessários à pesquisa com seres humanos, estabelecidos pela Resolução CNS 196/96, tanto nos planos individual - bebês e seus pais/ responsáveis - e institucional-CREI-, quanto junto à administração geral da rede de ensino a que pertencia o CREI. Conquistando aprovação no comitê de ética, CAAE 50892715.2.0000.5193.

\section{ANÁLISE: A INTEGRAÇÃO DO SELF DE UM BEBÊ QUE BRINCA NA CRECHE}

No CREl observado não havia uma infraestrutura favorável ao brincar dos bebês. Como tantas outras instituições, a escola funcionava num imóvel construído para fins residenciais, não arquitetado para a intervenção pedagógica. Não havia lugar adequado para a vivência de práticas corporais. As crianças brincavam numa pequena área calçada, usada como pátio. Além desse espaço, havia o berçário e a brinquedoteca, onde aconteciam todos os eventos realizados no CREI (reuniões, comemorações etc.).

Não obstante essa dimensão física, nas observações realizadas, identificou-se semelhança no brincar dos bebês: sempre adotavam uma mesma atitude fluente e focalizada nos diferentes espaços mencionados. Os bebês brincavam de modo intensamente diversificado e criativo. Com a atenção direta voltada para os objetos manipulados, eles criavam um espaço próprio, conseguindo transformar até mesmo o fisicamente precário em espaço para a atividade livre, aqui caracterizada como brincadeira.

Outra observação importante para entender-se a análise, nos episódios filmados: 0 brincar era uma atividade regular, quase sempre por iniciativa dos bebês, em diversas ocasiões (após o café, durante o lanche, no banho, após o lanche à tarde ou aguardando o retorno a suas casas). Durante a observação da rotina dos bebês, constatamos a precariedade de momentos específicos para brincar com eles. As monitoras estavam mais preocupadas em cumprir com os horários de banho, da alimentação e do sono. Pela manhã, inicialmente havia a acolhida com música, seguida da alimentação na sala do berçário; após a refeição, brincavam livremente e, no fim da manhã, acontecia o banho para o almoço e sono. À tarde eram levados à brinquedoteca ou ao pátio. Verificamos que os eventos ocorridos no berçário não eram organizados em função da demanda dos bebês, dificultando-se, assim, as construções que eles faziam sobre o mundo exterior.

Por vezes, eles brincavam de forma livre pela sala - explorando o ambiente com atenção multifocal - ou concentrados na manipulação de objetos, tanto individualmente (como se percebeu na maioria das vezes) como em interação com outros bebês (como foi observado sobretudo com os de mais idade).

De modo geral, nos episódios, em alguns momentos, a intensidade de peso engajada mudou de leve para forte. De acordo com a Labanálise, essa mudança pode significar que os bebês estavam se opondo a alguma coisa, posicionando-se. Já o fator tempo, em alguns momentos, foi predominantemente rápido: os bebês demonstravam uma atitude apressada, momentânea, o que foi interpretado como tentativa de sanar de imediato uma necessidade. Os fatores fluxo e espaço não sofreram considerada variação: os bebês sempre mantiveram atenção direta na ação e se moveram de modo livre.

Evidenciamos, dentre outros episódios observados repetidamente, uma brincadeira curiosa de "retira e coloca" (objetos de/em recipiente), vivida muitas vezes por diferentes bebês 
em relação aos fatores de movimento, peso e tempo. 0 episódio de brincadeira aqui analisado durou sete minutos e foi protagonizado por João, bebê cujo desempenho foi selecionado por ser interpretado como o mais autônomo no seu grupo, visto que suas brincadeiras sempre foram iniciadas e concluídas por iniciativa própria, de maneira voluntária, sem influência de adultos, servindo sua brincadeira como a melhor ilustração para o conceito de atividade lúdica espontânea. Dessa forma, o próprio João estabeleceu o espaço e tempo da atividade. Cabe ressaltar que a brincadeira foi escolhida em função de sua duração (longa, para um bebê), permitindo-nos considerar, sobretudo, o fluxo, o espaço e o tempo estabelecidos por João.

Com 11 meses, João, encontrava-se no centro da sala, sentado de costas para os dois berços, com a professora e quatro outros bebês. Segurava um balde com uma mão, entre suas pernas abertas, enquanto na outra tinha um patinho de borracha que ele colocava no balde e retirava. Nessa atividade, a cabeça do bebê estava para baixo e seu corpo inclinado para 0 balde, demonstrando sua concentração.

João experimentou trocar de mãos para segurar o balde na tentativa de retirar o patinho do balde com a mão oposta, sem conseguir. Tentou por mais de duas vezes, sem êxito. Soltou, então, o balde, dentro do qual colocou as duas mãos, com movimento forte e rápido, impondose, sem, todavia, conseguir retirar o pato.

Daí, novamente, trocou de mão, segurou o balde de forma a tentar emborcá-lo, mas interrompeu sua ação para coçar o nariz. Sem perceber que o pato caíra do balde, quando ele termina de coçar o nariz, o bebê foi pegar o pato, não o achando. Ele imediatamente olhou para o chão, para os lados, o que sugeriu a busca ao pato, até o encontrar. Nesse momento, segurou o objeto e o colocou cuidadosamente dentro do balde, sem o soltar, como se estivesse com cuidado para não o perder novamente.

Em seguida, João levantou a mão que segurava o pato, jogando-o com força para dentro do balde. 0 pato, porém, caiu no chão. Ao perceber que o brinquedo não estava dentro do balde, o bebê levantou as sobrancelhas, fazendo uma expressão de surpresa e imediatamente foi em direção ao pato, se arrastando, mas sem soltar o balde. Buscou pegar o pato com o balde algumas vezes, sem sucesso, e essas tentativas empurraram o pato. Com isso, o brinquedo se distanciou e nosso protagonista engatinhou em direção ao objeto lúdico. Ao chegar perto do pato, tentou arrastar o balde e colocar o pato dentro do balde; no entanto, o balde escapou de sua mão e ele, então, foi atrás do balde. De posse do balde, sentou-se e logo escolheu outro objeto para colocar dentro do balde (um carrinho, ao lado do pato).

O bebê iniciou tentativas de colocar o carrinho dentro do balde, todas frustradas, pois o objeto sempre caía fora do balde. Nessas tentativas, João desviou o olhar para o ambiente e encontrou o playground; ele, então, se desprendeu do que estava fazendo e foi em direção ao escorrega, levando consigo o balde e iniciando outra brincadeira.

\section{NO PRINCÍPIO É O LUDENS: O BRINCAR DO BEBÊ}

Discorrer sobre o brincar, pela perspectiva winnicottiana, implica primeiramente tratar das condições físicas necessárias à constituição do ambiente relacional necessário à integração do ser em formação, num processo não inato, vinculado ao desenvolvimento da capacidade de criar (WINNICOTT, 1975). 
O espaço físico do CREI era inadequado, por ser pequeno e inespecífico, tanto para o trabalho dos funcionários como para as crianças brincarem. Inexistindo aulas de Educação Física, constatamos iniciativas não planejadas da professora e berçaristas para interagirem com os bebês por meio de brincadeiras, muitas vezes fracassadas. Mesmo assim, os bebês brincavam sem interferência do adulto, de maneira absorvente, focalizada e simples.

Essa observação ratificou ser ainda necessário à Educação Física conquistar seu lugar na rotina das escolas como uma prática de valor pedagógico - não obstante o que Falkenbach; Drexsler; Werle (2006) constataram: a valorização das intervenções do(a) profissional de Educação Física pelas diretoras e professoras. Ora, as creches nasceram num tempo em que o cuidado de bebês não era pensado como atividade educativa, mas apenas como assistência social (OLIVEIRA et al., 1992) e os CREl, mesmo pensados sob uma ótica educativa, são herdeiros dessa história, pois, como afirmam Amorim et al. (2012, p.319), nessas unidades educacionais ainda "[...] não há ruptura com sentidos preexistentes, havendo sobreposição de práticas discursivas". Para superar práticas puramente assistenciais e valorizar o cerne educativo próprio às instituições da Educação Infantil, nestas é fundamental manter atividades específicas da Educação Física.

O fato de bebês brincarem livremente, a despeito de não lhes serem propostas atividades lúdicas intencionais pelas professoras e cuidadoras, devia-se, por nossa suposição, sobretudo à dimensão afetiva do ambiente relacional e à presença regular das educadoras, aliadas à disponibilidade dos brinquedos, que garantiram estabilidade, confiança e tranquilidade, não obstante a falta de condições infraestruturais mais adequadas. Isso possibilitava condições para os bebês exercitarem-se ou experimentarem calmaria.

Essa observação permite-nos ressaltar que o ambiente afetivo pode, inclusive, sobrepor-se ao material, complementando-o ou até o suplementando: os vínculos emocionais são capazes de adaptar favoravelmente 0 ambiente físico às necessidades básicas do bebê, permitindo-Ihe a possibilidade de perceber e relacionar-se com o outro, estabelecer contato com a realidade externa e, principalmente, constituir-se e relacionar-se consigo mesmo (MARCHESINI, 2010).

Esse aspecto evidencia o mérito do trabalho de profissionais da Educação Física na Educação Infantil, posto que eles (e elas) estão mais aptos(as) a planejar, executar e avaliar a brincadeira como atividade pedagógica, com grande potencial de comunicação e interação corporal, formando vínculos emocionais, contribuindo para melhor compreensão dos sujeitos (FALKENBACH; DREXSLER; WERLE, 2006). Com esse fim, o(a) professor(a) de Educação Física deve oferecer ao bebê um espaço físico confortável e bem organizado, um ambiente suficientemente bom que permita ao bebê viver toda experiência com o mínimo de interrupção possível. Ora, para isso, será necessário criar e testar estratégias e intervenções pedagógicas que compreendam os significados de movimento, provocando configuração ampla dos sujeitos.

Destaca-se que João manteve sua concentração, envolvido na ação de tal forma que foi indiferente aos acontecimentos ao seu redor. Winnicott (1975, p. 76) já discutia esta questão, ao afirmar: "a criança que brinca habita uma área que não pode ser facilmente abandonada, nem tampouco admite facilmente intrusões". Essa área é um indicativo da constituição do eu, com vistas à integração do self, pois a atenção focalizada a algum objeto ou situação significa estar presente, não alheio às exigências do brincar (GOMES-DA-SILVA, 2016). 
Percebe-se que João brincou de maneira deliberada, em uma ação difícil de ser interrompida e, apesar de estar alerta aos acontecimentos ao seu redor, possuía o olhar direto, voltado para os objetos manipulados, em uma atitude focalizada, quase indesviável. Ao envolverem-se no brincar, os bebês possuem uma atitude não consciente do espaço ao redor, estando totalmente voltados para a manipulação dos objetos, para a emoção interior. "A conduta lúdica nem é de controle, nem de submissão, mas, da unidade experimentada na absorção do jogar" (GOMES-DA-SILVA, 2016, p.157).

Isso evoca o que Wallon (2008) afirmou, ao considerar que o estado de contemplação e o olhar do bebê implicam o ato de fundir-se em espetáculo, de forma não passiva. Quando o bebê contempla as coisas, ele está em estado de impregnação perceptivo-motor, sua musculatura trabalha durante todo o tempo em que olha. A excitação não é puramente cerebral, mas se espalha pelos músculos, que são a sede de uma atividade por vezes sentida intensamente pelo sujeito e, na maioria das vezes, imperceptível para os outros.

O estudo de Amorim, Anjos e Rossetti-Ferreira (2012) aponta para o olhar do bebê como uma atividade bastante ativa e promotora de aprendizagens e interações. Outras pesquisas, como as de Rosetti-Ferreira et al. (2011), Elmor (2009) e Belini; Fernandes (2007), identificaram o olhar do bebê como recurso comunicativo, relacional. No entanto, reconhecese a necessidade de novos estudos que enfoquem o olhar do bebê enquanto elemento de intencionalidade, recurso de aprendizagem e comunicação com o mundo, contribuindo para a integração do eu.

Infere-se também, pela conduta de João, que ele sentia a necessidade de estar de posse de um objeto e, com isso, exercer algum poder, estando o objeto à disposição de seus propósitos de autoexpressão. Isso é identificado, por exemplo, no instante em que o bebê colocou o pato no balde, mas não o soltou: parecia não querer perdê-lo de novo. Mesmo quando o jogou com força para dentro do balde, perdendo o domínio do pato, imediatamente foi em direção a ele, sem soltar o balde.

Com isso, vê-se como o sentimento de domínio do objeto está associado ao sentimento de ilusória onipotência: nesse contexto, pode-se dizer que o bebê possuía a intenção para agir, ele sentia ter o controle do ambiente, era ele quem criava. Esse sentimento é fundamental, segundo Winnicott (1975), pois anima o sujeito a identificar-se com um eu que, em verdade, não é natural nem todo-poderoso, mas criado a partir da fragilidade inicial humana. Além disso, o uso do objeto implica que este faça parte da realidade externa, com propriedades que independem do sujeito. Percebemos isto no momento em que João tentou, por várias vezes, pegar o pato com o balde, apenas se distanciando do brinquedo.

Quando a criança possui a capacidade de encontrar os objetos, ou seja, a segurança que a sustenta, tem uma relação criativa com a realidade externa, conforme Winnicott (2000), o objeto importa não apenas por substituir a mãe adaptada ao bebê, mas por ter uma realidade própria, advinda de sua materialidade e, paradoxalmente, do fato de ser criado pelo indivíduo: é o objeto objetivamente percebido. Mais importante que o objeto é o sentido da sua realidade:

É verdade que a ponta do cobertor (ou o que quer que seja) é simbólica de algum objeto parcial, tal como o seio. No entanto, o importante não é tanto seu valor simbólico, mas sua realidade. 0 fato de ele não ser o seio (ou a mãe), embora real, é tão importante quanto o fato de representar o seio (ou a mãe) (WINNICOTT, 2000, p. 19). 
Portanto, no episódio, o que João exercitava era capacidade de encontrar, não necessariamente um objeto específico. E, nessa busca de encontrar, aparente no brincar, todo o seu corpo estava envolvido. Logo, é preciso considerar a importância do efeito do material e a funcionalidade dos brinquedos sobre a atividade da criança. 0 caso dos brinquedos automatizados e autômatos serve como exemplo negativo, pois, como lembra Gomes-da-Silva (2005, p.84), esses brinquedos "[...] movem-se a partir de uma bateria ou por fricção, de modo que a energia em ação não é a do brincante. Toda ação do brinquedo requer um mínimo de energia cinética daquele que brinca".

Esse aspecto acentua que os objetos oferecidos à brincadeira devem ser de diferentes formas, tamanhos e texturas, possibilitando ao corpo do bebê manifestar sua ordem, seu tempo, suas condições internas, seus elementos constituintes, suas fantasias e, principalmente, seus desejos - culminando, por fim, na constituição de um eu, base da experiência do self.

Ratifica-se que quem torna o brinquedo educativo não é o professor, mas as mãos do brincante ao estabelecer o diálogo entre 0 que foi intencionado pelo mundo adulto e 0 que foi vivido pela criança, marcado pelo desejo do brincante (GOMES-DA-SILVA, 2016). $\mathrm{O}$ (a) educador(a), nessa abordagem pedagógica da PC, faz parte do ambiente que propiciará condições favoráveis para que, havendo diferenciação de situações de movimento, em resposta a elas, o bebê vá gradualmente integrando seu self.

Ao ser exposto a diferentes situações, como parece ter sido o caso de João no episódio, foram criadas condições para a experiência da livre exploração dos sentidos - (re) conhecer textura, cheiro, cor dos objetos; e a formação dos sentimentos como as sensações de continuidade e confiança na interação com os universos material e emocional, vital para a integração dos construtos psíquicos e a afirmação de desejos.

No episódio, João executava a brincadeira a sua própria maneira, tendo liberdade de escolha. Quando, por exemplo, ele decidiu trocar de mãos para segurar o balde, verificou-se a tomada de decisão. Deu seu ritmo à brincadeira, ao tentar algumas vezes retirar o objeto dentro do balde, com a mão trocada, até desistir e realizar outro movimento. Então, nesta ação, houve mobilidade do bebê e tolerância em relação às frustrações, só desistindo após várias tentativas. A duração da brincadeira também foi decidida pelo bebê, assim como a mudança para outra atividade.

Nesse contexto, pode-se afirmar que "[...] através da espontaneidade e das experiências reais o si-mesmo verdadeiro torna-se realidade viva para esse bebê" (MARCHESINI, 2010, p. 52). Então, deixamos o bebê com seu objeto, em cuja relação João encontrou paz, naquele misterioso espaço entre uma realidade pessoal e a realidade de fato, compartilhada com outros. O recorte aqui explorado ratifica a compreensão de que a conquista da unidade pessoal só continuaria a acontecer se o bebê se mantivesse ativo e descobridor.

Para Falkenbach; Drexsler; Werle (2006), os profissionais que atuam na Educação Infantil consideram o brincar importante enquanto estiver a serviço de uma aprendizagem (valores, leitura, escrita, cálculo): devido à excessiva preocupação com o desenvolvimento cognitivo e formativo dos alunos, os(as) professores(as) acabam por perder a sensibilidade em relação aos desejos e às necessidades das crianças.

Nosso estudo vem reforçar e propor pela Pedagogia da Corporeidade a compreensão do brincar como produção de linguagem que exprime aqueles desejos e favorece o criar 
na circunstância por meio de ações motoras. Deve-se perceber o bebê não só como ser cognoscitivo, mas principalmente brincante, de modo a reconhecer a necessidade da Educação Física na Educação Infantil. Esse reconhecimento abrirá caminhos para superar a dicotomia corpo-mente que se instala, no que diz respeito aos primeiros anos da criança, já na escola que a acolhe. Ora, a criança não é só cérebro ou linguagem articulada, o bebê é, desde sempre, movimento, ação, linguagem criativa. Esquecer-se disto concorre para reduzir ou mesmo inibir a expressividade corpórea do bebê.

A Educação Física Escolar para bebês, com sua sistematização, espacialidade e temporalidade, numa abordagem da Pedagogia da Corporeidade, deve se abrir para a proposição de múltiplas experiências lúdicas, que absorvam o jogador, desafiando-o por meio da oferta de ambientes ricos e diversos, favoráveis à integração dos sujeitos ao meio. Os modelos tradicionais de intervenção da Educação Física, segundo Surdi; Melo; Kunz (2016), valorizam modos de interação que só mais tarde podem, eventualmente, ganhar cunho pedagógico como brincadeiras competitivas e sempre direcionadas para buscar um vencedor. $O$ adulto dita a importância dada à brincadeira, esta não advém das crianças e isso diminui o significado e a importância que o brincar, enquanto atividade livre, expressiva e exploratória, tem em relação à criança.

Portanto, o(a) professor(a) de Educação Física trabalhando com bebês precisa de formação para que, em sua prática pedagógica, seja capaz de oportunizar a liberdade de escolha, permitir produzir sua ação, responder ao entorno de forma criativa, estar no domínio de um objeto, aprender a organizar-se com a circunstância, revelando, assim, sua capacidade de produção de sentido. Essa é nossa proposta educativo-terapêutica pela Pedagogia da Corporeidade, já que o brincar é a garantia da saúde da criança que cresce.

Terapêutico é descobrir o self, visto ser pelo brincar que o bebê é capaz de descobri-lo. Destacamos dois motivos, primeiro porque ao brincar o bebê está se satisfazendo - "Brincar, essencialmente, satisfaz" (WINNICOTT, 1975, p. 77). A satisfação é fundamental para a integração do self, porque permite ao sujeito perceber os sentimentos como seus, tornando-se uma experiência pessoal, possibilitando-o, assim, a ir se integrando e se sentindo vivo e real. "Sentir-se real é mais do que existir, é descobrir um modo de existir como si-mesmo, relacionarse aos objetos como si-mesmo e ter um si-mesmo para o qual retirar-se para relaxamento" (WINNICOTT, 1975, p. 61).

Segundo, porque descobre o self pela autoexpressão e autoexperimentação. Em João brincando vemos, por sete longos minutos, uma produção de sentido na contemplação e na manipulação de pato e balde. No esforço para inserir e manter o patinho no balde, o bebê empregou gestos (surpresa nas feições), posturas (corpo projetado sobre o balde) e ações (retenção do balde, busca repetitiva por alcançar o pato com o balde, mãos projetadas no interior do balde para recuperar o pato) que revelaram agressividade e seu controle, com a consequente satisfação e o exercício de tolerância à frustração, inferidos pela repetição, mas também pelo abandono da atividade, que pareceu exaurir-se.

\section{CONCLUSÃO}

O episódio aqui analisado ajudou a compreender a contribuição do brincar para a integração do sujeito, já nos primeiros dois anos de vida, tendo como base a teoria winnicottiana. 
Para isso, analisamos uma atividade livre do bebê em suas expressões e movimentos, no ambiente de um CREI. A análise leva-nos a ratificar o entendimento de que o brincar é a fundação e a manifestação primeira da atividade criativa, sendo o lúdico experiência de confiança e relaxamento, de concentração e escolhas, de controle do objeto e autocontrole, com decorrente satisfação. Assim, ele é altamente significativo para a formação da personalidade saudável e a integração do sujeito psíquico, principalmente nos primeiros anos de vida.

O brincar, então, tem um papel insuperável de animar o encontro consigo mesmo e com o outro, partindo da Pedagogia da Corporeidade, gerindo impulsos prazerosos e agressivos, expressando desejos, antecipando e elaborando emoções, de forma a garantir as raízes do sentido de viver.

A prática pedagógica docente da Educação Física na Educação Infantil deve recorrer a essa fonte de intervenções: precisa motivar, acolher e delimitar o espaço físico e o psíquico para garantir as condições ao brincar livre e criativo de bebês. Professores(as) também devem estar atentos(as) aos signos emitidos pela criança, e ser capazes de atender às necessidades do bebê que, nessa fase, ainda é extremamente dependente, sendo imprescindível a presença constante de um adulto, capaz de interpretar esta comunicação, para, então, fomentar um desenvolvimento emocional saudável.

Uma vez que o bebê ainda está em processo de desligamento de sua mãe, necessita encontrar, no ambiente escolar e na figura do(a) professor(a), meios facilitadores para o brincar. Portanto, o(a) professor(a) deverá construir um relacionamento de afetividade, confiabilidade e segurança. Suas aulas devem ocorrer na segurança ofertada da brincadeira livre, promovendo 0 ato criativo, permitindo ao bebê escolher livremente, ter direitos sobre o objeto, envolver-se naquele estado de quase alheamento e satisfação. Com isso, possibilitará o desenvolvimento da capacidade de sentir-se uno, de integrar suas experiências e formar a sua personalidade.

Nesse sentido, tomar o brincar dos bebês como uma necessidade das experiências de aprendizagem na Educação Infantil concorrerá, inclusive, para questionar os fundamentos das práticas e representações tradicionais, responsáveis pela constituição de práticas pedagógicas menos eficazes ou, pior, até mesmo repressivas, como registra a história da constituição das creches.

Por isso, uma recomendação final decorrente deste trabalho recai sobre a imprescindível formação profissional: é através do conhecimento teórico, da observação sistemática de bebês e da autoinvestigação (voltada para a capacidade de emocionar-se positivamente com bebês e por eles experimentar empatia) que se podem vislumbrar docentes mais comprometidos com a valorização do brincar na Educação Infantil, tomado como princípio de humanização.

\section{REFERÊNCIAS}

ABRAM, Jan. A linguagem de Winnicott. Rio de Janeiro: Revinter, 2000.

AMORIM, Katia de Souza; ANJOS, Adriana Mara dos; ROSSETTI-FERREIRA, Maria Clotilde. Processos interativos de bebês em creche. Psicologia: Reflexão e Crítica, v. 25, n.2, p 378389, 2012. 
AMORIM, Katia de Souza et al. O bebê e a construção de significações, em relações afetivas e contextos culturais diversos. Temas em Psicologia, v.20, n.2, p 309-326, 2012.

BELINI, Aline Elise Gerbelli; FERNANDES, Fernanda Dreux Miranda. Olhar de bebês em desenvolvimento típico: correlações longitudinais encontradas. Sociedade Brasileira de Fonoaudiologia, v.12, n.3, p 165-173, 2007.

BERNARDINO, Leda Fisher; KAMERS, Michele. A creche e o brincar: alternativas para a educação no primeiro ano de vida. Estilos da Clínica, v.8, n.15, p 48-57, 2000.

BORDIN, Rafaela; SOUZA, Cícera Andréa de; KUNZ, Eleonor. O brincar heurístico: pensando a educação física para bebês. In: CONGRESSO SUL BRASILEIRO DE CIÊNCIAS DO ESPORTE, 7, 2014. p. 1-12. Anais... Disponível em: <http://congressos.cbce.org.br/index.php/7csbce/2014/ paper/viewFile/5887/3137>. Acesso em: 5 mar. 2016.

BRESSANI, Maria Cristina; BOSA, Cleonice; LOPES, Rita Sobreira. A responsividade educadora-bebê em um berçário: um estudo exploratório. Revista Brasileira Crescimento Desenvolvimento Humano, v.17, n. 3, p. 21-36, 2007.

Costa, Sandra Barbosa. 0 andar como expressão da atitude pedagógica do professor de Educação Física. 2010. 124f. Dissertação (Mestrado) - Programa Associado de Pós-graduação em Educação Física, UPE/UFPB, Recife-PE, 2010.

DIAS, Elsa Oliveira. A teoria do amadurecimento de D.W. Winnicott. Rio de Janeiro: Imago, 2003.

ELMÔR, Larissa de Negreiros Ribeiro. Recursos comunicativos utilizados por bebês em interação com diferentes interlocutores, durante processo de adaptação à creche: Um estudo de caso. 2009. 205 f. Dissertação (Mestrado) - Programa de Pós-graduação em Psicologia, FFCLRP/USP, Ribeirão Preto-SP, 2009.

FLICK, Uwe. Métodos qualitativos na investigação científica. Lisboa: Monitor. 2005.

FERNANDES, Ciane. 0 Corpo em Movimento: o sistema Laban/Bartenieff na formação e pesquisa em artes cênicas. São Paulo: Annablume, 2006.

FALKENBACH, Atos Prinz; DREXSLER, Greice; WERLE, Verônica. Investigando a Ação Pedagógica da Educação Física na Educação Infantil. Movimento, v.12, n. 1, p. 81-103, jan./ abr. 2006.

GIL, Antônio Carlos. Como elaborar projetos de pesquisa. 4. ed. São Paulo. Atlas, 2002.

GOMES-DA-SILVA, Pierre Normando. Jogo, Cultura e Pulsão: uma semiótica dos brinquedos e dos brincantes. In: VITA, Ivone de Barros; ANDRADE, Fernando César Bezerra de (Orgs.).

(Des) fiando a trama: a psicanálise nas teias da educação. São Paulo: Casa do Psicólogo, 2005. p. 77-96.

GOMES-DA-SILVA, Pierre Normando. 0 jogo da cultura e a cultura do jogo: por uma semiótica da corporeidade. João Pessoa: Ed. Univ. UFPB, 2011.

GOMES-DA-SILVA, Pierre Normando. Pedagogia da corporeidade: o decifrar e o subjetivar na educação. Tempos e espaços em educação, v. 13, p. 15-30, 2014.

GOMES-DA-SILVA, Pierre Normando. Semiótica dos jogos infantis. João Pessoa: Ed. Univ. UFPB, 2015. 
GOMES-DA-SILVA, Pierre Normando. Mundos sem fim do brincar: de Winnicott para depois. In: BANDEIRA, Graça. (Org.). Viver Criativo: escritos de Educação com Winnicott. Curitiba: CRV, 2016. p.157- 186.

GONÇALVES, Danielle Menezes de Oliveira. O brincar do bebê e a constituição do sujeito. 2012. 110 f. Dissertação (Mestrado) - Programa Associado de Pós-graduação em Educação Física, UPE/UFPB, Recife-PE, 2012.

LABAN, Rudolf. Domínio do movimento. São Paulo: Summus, 1978.

LOPARIC, Zeljko. O animal humano. Natureza Humana, v. 2, n.2, p 351-397, 2000.

MARCHESINI, Anna Lúcia Sampaio. A constituição do si-mesmo: uma abordagem winnicottiana. 2010. 85 f. Dissertação (mestrado) - _Programa de Estudos Pós-Graduados em Psicologia: Psicologia Clínica, PUC-SP, São Paulo, 2010.

MINAYO, Maria Cecília de Souza. O Desafio do Conhecimento: pesquisa qualitativa em saúde. São Paulo/Rio de Janeiro: Hucitec/Abrasco, 1996.

MOMMENSOHN, Mara; RENGEL, Lenira Peral. 0 corpo e o conhecimento: dança educativa. São Paulo: FDE, 1992. (Série Ideias,10).

NYLANDER, Pamella Isabela Alvarez et al. Educadores infantis: aspectos da formação profissional e do trabalho em creche. Temas psicologia, v. 20, n. 2, p 571-584, 2012.

OLIVEIRA, Zilma Ramos et al. Creches: crianças, faz de conta \& cia. 7. ed. Petrópolis, RJ: Vozes, 1992.

OLIVEIRA, Vera Barros. O brincar e a criança do nascimento aos seis anos. Rio de Janeiro: Vozes, 2009.

OLIVEIRA, Danielle Menezes de; GOMES-DA-SILVA, Pierre Normando. O brincar do bebê: notas winnicottianas para uma prática educativa criativa. In: HERMIDA, Jorge Fernando; BARRETO, Sidirley de Jesus (Org.). Educação Infantil: temas em debate. João Pessoa, Ed. UFPB, 2013. p. 75-97.

PÉREZ-RAMOS, Aidyl Queiroz. A criança pequena e o despertar do brincar (primeiros dois anos de vida). In: OLIVEIRA, Vera Barros (Org.). 0 brincar e a criança do nascimento aos seis anos. Rio de Janeiro: Vozes, 2009. p 57-94.

ROSSETTI-FERREIRA, Maria Clotilde et al. Peer relations in Brazilian daycare centers: A new focus for early childhood education. In: KERNAN, Margaret; SINGER, Elly (Eds.). Peer relationships in early childhood education and care. London: Routledge Taylor; Francis Group, 2011. p. 74-87.

SILVA, Kelly Grace da; CINTRA, Thalita Tomázia de Alcântara; PINHEIRO, Maria do Carmo Morales Pinheiro. Bebês em movimento: estágio da educação física na educação infantil.

Cadernos de Formação RBCE, v.3, n.1, p. 46-56, 2012.

SIMON, Heloisa dos Santos; KUNZ, Eleonor. O brincar como diálogo/pergunta e não como resposta à prática pedagógica. Movimento, v. 20, n. 1, p. 375-394, jan./mar. 2014.

SURDI, Aguinaldo Cesar; MELO, José Pereira de; KUNZ, Eleonor. O brincar e o se-movimentar nas aulas de educação física infantil: realidades e possibilidades. Movimento, v. 22, n. 2, p. 459-470, abr./jun. 2016. 
VASCONCELOS, Cleido Roberto Franchi et al. A incompletude como virtude: Interação de bebês na creche. Psicologia: Reflexão e Crítica, v, 16, n.2, p 293-301, 2003.

WALLON, Henri. Do ato o pensamento: ensaio de psicologia comparada. Petrópolis, RJ: Vozes, 2008.

WINNICOTT, Donald Woods. Da pediatria à psicanálise: obras escolhidas, Rio de Janeiro: Imago, 2000.

WINNICOTT, Donald Woods. A família e o desenvolvimento individual. 3. ed. São Paulo: Martins Fontes, 2005.

WINNICOTT, Donald Woods. O brincar e a realidade. Rio de Janeiro: Imago, 1975. 
